\title{
Multimodal evoked potentials in chronic migraine
}

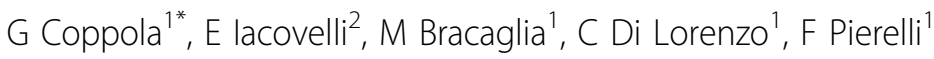 \\ From The European Headache and Migraine Trust International Congress \\ London, UK. 20-23 September 2012
}

\section{Background and objectives}

Chronic migraine $(\mathrm{CM})$ is a disabling health condition. The exact pathophysiological mechanisms are not completely clarified, but a crucial role was attributed to central sensitization. When still episodic, migraine is characterized by a deficient habituation to any kind of sensorial stimulations between attacks, and by an ictal EPs normalization. Less is known about how central sensitization alter this electrocortical profile in CM. Materials \& Method - Fifteen episodic and 14 chronic migraine patients underwent median-nerve somatosensory (SSEPs) (right stimulation, 500 sweeps, 4.4 repetition rate, 1.2 motor threshold) and visual (VEPs) evoked potentials (right eye stimulation, 600 sweeps, 3.1 repetition rate, 15 min of arc check) randomly during the same recording session. Patients groups were compared to a group of 22 healthy volunteers (HV) of comparable age and gender distribution. Habituation was calculated as the slope of the linear regression between block 1 to 3 for SSEPs or between block 1 to 6 for VEPs.

\section{Results}

In episodic migraineurs recorded between attacks, 1st amplitude blocks of VEPs and SSEPs were respectively reduced $(\mathrm{p}=0.05)$ or tended to be reduced $(\mathrm{p}=0.07)$, but thereafter both failed to habituate along subsequent blocks of responses. In CM patients initial VEP and SSEP amplitudes were in the same range of activation of $H V(p>0.05)$, then habituated normally during stimulus repetitions. When data of MO and CM patients were combined, the SSEP 1st amplitude block was positively $(\mathrm{r}=0.411, \mathrm{p}=0.04)$ and the slope negatively $(r=-0.624, p=0.001)$ correlated with the monthly number of days with headache.

Sapienza University of Rome Polo Pontino, Department of Medico-Surgical

Sciences and Biotechnologies, Latina, Italy

Full list of author information is available at the end of the article

\section{Conclusion}

Our results show in CM abnormalities that are also reported during attacks in episodic migraineurs, namely response habituation, which contrasts to its lacking detected between attacks. This suggests that from an electrophysiological point of view, CM looks like a never ending migraine attack.

\section{Author details}

'Sapienza University of Rome Polo Pontino, Department of Medico-Surgical Sciences and Biotechnologies, Latina, Italy. ${ }^{2}$ Sapienza University of Rome, Department of medico-surgical sciences and biotechnologies, Neurology section, Rome, Italy.

Published: 21 February 2013

doi:10.1186/1129-2377-14-S1-P122

Cite this article as: Coppola et al:: Multimodal evoked potentials in chronic migraine. The Journal of Headache and Pain 2013 14(Suppl 1): P122.

\section{SpringerOpen ${ }^{\circ}$}

(c) 2013 Coppola et al; licensee Springer. This is an Open Access article distributed under the terms of the Creative Commons Attribution License (http://creativecommons.org/licenses/by/2.0), which permits unrestricted use, distribution, and reproduction in any medium, provided the original work is properly cited.
Submit your manuscript to a SpringerOpen ${ }^{\circ}$ journal and benefit from:

- Convenient online submission

- Rigorous peer review

- Immediate publication on acceptance

- Open access: articles freely available online

- High visibility within the field

- Retaining the copyright to your article

Submit your next manuscript at $>$ springeropen.com 